\title{
Seed Pelleting Technology to Tef [Eragrostis tef (Zucc.)] Improvements and Its Importance for Agronomic Practice: A Review
}

\author{
Abdisa Mekonnen \\ Ethiopian Institute of Agricultural Research, Holeta Agricultural Research Center, P.O. Box. \\ 2003 Addis Ababa, Ethiopia
}

\begin{abstract}
Tef in Ethiopia, among the cultivated food crops grown it ranks first, with an estimated production area of $3,023,283.5$ ha and a mean productivity of $1.75 \mathrm{tha}^{-1}$. However, despite its importance in Ethiopia, tef yields are low. In the production year 2017-2018, yields were $1.7 \mathrm{t} \mathrm{ha}^{-1}$ significantly lower than other cereals, such as: maize (3.95 $\mathrm{t} \mathrm{ha}^{-1}$ ), sorghum and wheat (both $2.72 \mathrm{t} \mathrm{ha}^{-1}$ ). A knowledge on the use of pelleted seeds in improving the productivity of the tef crop by seed sowing with a minimum time wastage, reduce labor costs, for the use of planting machine to boost the yield of the crop in the country particularly tef grower farmers, investors and other stake holders. From this, to review seed pelleting technology and its importance for agronomic practices and to generate information on seed pelleting for future research direction. The small size of tef seed possess problems during sowing, and indirectly during weeding and threshing. Seed pelleting is the process of enclosing a seed inside a small quantity of inert material just large enough to produce a globular unit of standard size to facilitate planting. Small and irregularly shaped seed can now be treated as larger and round-shaped. Many crop seeds are small and irregular in shape which does not permit the accurate metering by mechanical planting equipments. Pelleting improves the chances of successful germination and seedling establishment under field condition. The pelleting technique increases and homogenizes seed size, but it is essential to determine the physical and physiological characteristics of pelleted seeds. Pellet improvements over the last 10 years include increased $\mathrm{O}_{2}$ penetration/availability, wider pellet density range, pellet loading, better field visibility. Because of the large increase in volume obtained when seeds are pelleted, pellets have been shown to be effective carriers of plant Protects. Generally application seed pelleting technology for small seed size crops particularly, tef it important for proper planting and maintain planting density of the crop. To this end, research for scientific evident is needed to this technology in the future.
\end{abstract}

Keywords: pelleting technology, Seed pelleting, enclosing a seed

DOI: $10.7176 / \mathrm{JNSR} / 11-24-01$

Publication date: December $31^{\text {st }} 2020$

\section{INTRODUCTION}

Tef [Eragrostis tef(Zucc.) Trotter] is the most important cereal crop in the Horn of Africa, especially in Ethiopia, where the last two decades have seen tremendous increases in both the total area devoted to the crop and its production. Tef (Eragrostis tef (Zucc.) trotter) is an allotetraploid $(2 \mathrm{n}=4 \mathrm{x}=40)$, small cereal grain crop that belongs to the family Poacea, sub-family Eragrostoideae, tribe Eragrostidae and genus Eragrostis (Seyfu, 1997). Ethiopia is the center of diversity and origin of tef (Vavilov, 1951). Tef is a staple food supporting some 50 million people in Ethiopia. Currently, the crop is increasingly receiving global attention for its nutritional advantages because it is rich in nutrients and is gluten free. It contains $11 \%$ protein, $80 \%$ complex carbohydrates, $3 \%$ fat (Piccinin, 2002).

Tef has become globally known and various products are available in Europe and North America as health foods especially for persons with gluten intolerance (Saturni et al., 2010). Recently, limited levels of tef cultivation have started in the USA, the Netherlands and Israel. Tef straw is also a valuable source of livestock feed. In South Africa, India, Pakistan, Uganda, Kenya and Mozambique tef is mainly grown as a forage or pasture crop (Kebebew et al., 2011). Interestingly, unlike other cereals, tef is little affected by field and storage pests and diseases (Seyfu, 1997). Among the cultivated food crops grown in Ethiopia, it ranks first with an estimated production area of $3,023,283.50$ hectares of land, which is equivalent to $30 \%$ of the total area allocated to cereals and a mean productivity of $1.75 \mathrm{t} \mathrm{ha}^{-1}$ (CSA, 2018). Tef has the genetic potential to yield up to $6 \mathrm{t} \mathrm{ha}^{-1}$ (Seyfu, 1993). Among the cereals tef is grown by $6,771,977$ households, occupying more than three million hectare of land (CSA, 2018). The crop has desirable traits to cope with the changing climate that generate household income, and fulfilling nutritional needs of farmers (Kebebew et al., 2015).

Tef is used in various forms by Ethiopians. Its usage dominantly in the form of injera, unleavened pan cake made of tef flour, which is the mainstay (basis) of Ethiopian diet. It is also consumed in the form of porridge and bread. Tef is gluten-free, rich in phosphorous, copper, aluminum and thiamine and is an excellent source of protein, amino acids and carbohydrates. Tef is higher in calcium, iron and zinc content than corn, wheat, or rice (Baye, 2014). 
According to Gamboa and Ekris's, (2008) study on the nutritional and health aspects of tef, it was found the small grain is too small to refine and tef flour includes the bran and germ, which are "the most nutritious parts of any grain". Another health related benefit of tef is the high in fiber content (Bay, 2014). According to Zung, (2004) Stated that is particularly important in dealing with diabetes and assisting with blood sugar control. Its straw is a nutritious and highly preferred feed for livestock compared to the straw of other cereals particularly during dry season. Besides its local use, it is the major cash earning crop for the farming community as market price for both its grain and straw is higher compared to other cereal crops, also it is among export commodity at national level.

However, despite its importance in Ethiopia, tef yields are low. In the production year 2012-2013, yields were 1.4 metric tons ha ${ }^{-1}$ significantly lower than other cereals, such as maize ( $\left.3.1 \mathrm{mt} \mathrm{ha}^{-1}\right)$, sorghum and wheat (both $2.1 \mathrm{mt} \mathrm{ha}^{-1}$ ) (CSA 2013). This low tef yield is seemingly explained by the limited knowledge about possible avenues for improving tef productivity, combined with problems inherent to tef botany. Tef research has received limited national and international attention, the latter presumably because of its localized importance in Ethiopia (Takegn et al., 2011). Moreover, tef yields are low because of agronomic constraints that include lodging, low modern input use, sowing methods and high post-harvest losses (Habtegebrial et al., 2007).

Recently it has been argued that the traditional sowing technology is a major constraint to increased tef productivity (Takegn et al., 2011). Farmers typically plant tef by broadcasting, scattering tef seed by hand at a high seed rate. Alternative planting methods, such as row planting seeds or transplanting seedlings, in which the seed rate is reduced and more space between plants is given, are seen as being superior to traditional broadcasting (Takegn et al., 2011, Fufa et al., 2011). Experiments on these alternative planting methods in controlled settings have shown large and positive impacts on tef yields (Takegn et al., 2011, Fufa et al. 2011). As a consequence, in 2013 the Ethiopian government rolled out a nationwide campaign to promote the use of improved technologies for tef production, including row Planting, aiming to scale up their adoption to almost 2.5 million tef producing farmers. However, the impacts of the widespread promotion campaign of row planting of tef, in particular, on land and labor productivity are unknown. This is mainly due to a lack of reliable and objective farm level data. Moreover, no systematic effort has yet been put into examining farmers' perceptions after they experimented with the new sowing techniques. Seed pelleting technology is an optional for accurate planting especially small seeded crops. The rationale for seed pelleting is to take a seed that is light in density and turn it into a seed with a pellet around it that makes the seed heavier, more uniform and as perfectly round as possible. A planter will be able to plant that seed/pellet in the most accurate and precise way that is feasible (Kubik, 2002).

The most essential phase of precision planting is the singling of seeds for exact placement at a pre-determined depth and spacing in the soil with a uniform coverage and at a reasonable planting speed. Singling is difficult for seeds which are low in density and irregular in shape. To overcome these difficulties seed pelleting is advocated (Bharathi et al., 2003). A knowledge on the use of pelleted seeds in improving the productivity of the tef crop by seed sowing with a minimum time wastage, reduce labor costs, for the use of planting machine to boost the yield of the crop in the country particularly tef grower farmers, investors and other stake holders. Therefore, the objective of this review was to assess seed pelleting technology and its importance for agronomic practices.

\section{LITRATURE REVIWE}

\subsection{Ecological Distribution of Tef}

Tef is primary originated and traditionally harvested grain in Ethiopia, when first domesticated between 4000$1000 \mathrm{BC}$ (Rose, 2011). Tef (Eragrostis tef (Zucc.) trotter) is an allotetraploid ( $2 \mathrm{n}=4 \mathrm{x}=40$ ), small cereal grain crop that belongs to the family Poacea, sub-family Eragrostoideae, tribe Eragrostidae and genus Eragrostis (Ketema, 1997). Seeds are small in size, and weight of 1000 seeds is 0.3 to $0.4 \mathrm{~g}$. The crop is versatile in that it is adapted to diverse agro-ecological conditions due in part to its resilience to abiotic stresses such as drought and water logging (Kebebew et al., 2011). Tef grows under a wide range of ecological conditions from sea level to 2800 meter above sea level. It performs best at altitudinal ranges of 1800 to 2100 meter above sea level. The rainfall requirement of the crop varies from 450 to $550 \mathrm{~mm}$.. Tef requires temperatures of 10 to $27^{\circ} \mathrm{C}$ and flowers best under 12 hour day length (Seyfu, 1997).

\subsection{Morphology of Tef}

Tef is an annual, leafy, tufted grass that reaches a height of 150 to $200 \mathrm{~cm}$ at maturity. The culms are fine, erect, simple or sparsely branched, prone to lodging. The root system is shallow and fibrous. Its leaves are glabrous, linear, 25 to $45 \mathrm{~cm}$ long x 0.1 to $0.5 \mathrm{~cm}$ wide. The seed head is a long panicle of 10 to $65 \mathrm{~cm}$ bearing 10 to 40 slender racemes, which may be either very loose or very compact. Panicles bear 30 to 1100 spikelets. Fruits are ellipsoid, minute (1 to $1.5 \mathrm{~mm}$ x 0.5 to $1 \mathrm{~mm}$ ), yellowish to white to deep brown caryopsis (grain) (Seyfu, 1997). Tef is possibly the smallest cereal grain, with an average length of about $1 \mathrm{~mm}$. The average thousand kernel weight of 12 tef varieties is $0.264 \mathrm{~g}$ (Geremew, 2007). The word "tef" is connected by folk etymology to the Ethiopian Semitic root "tff", which means "lost", because of the small size of the grain. 


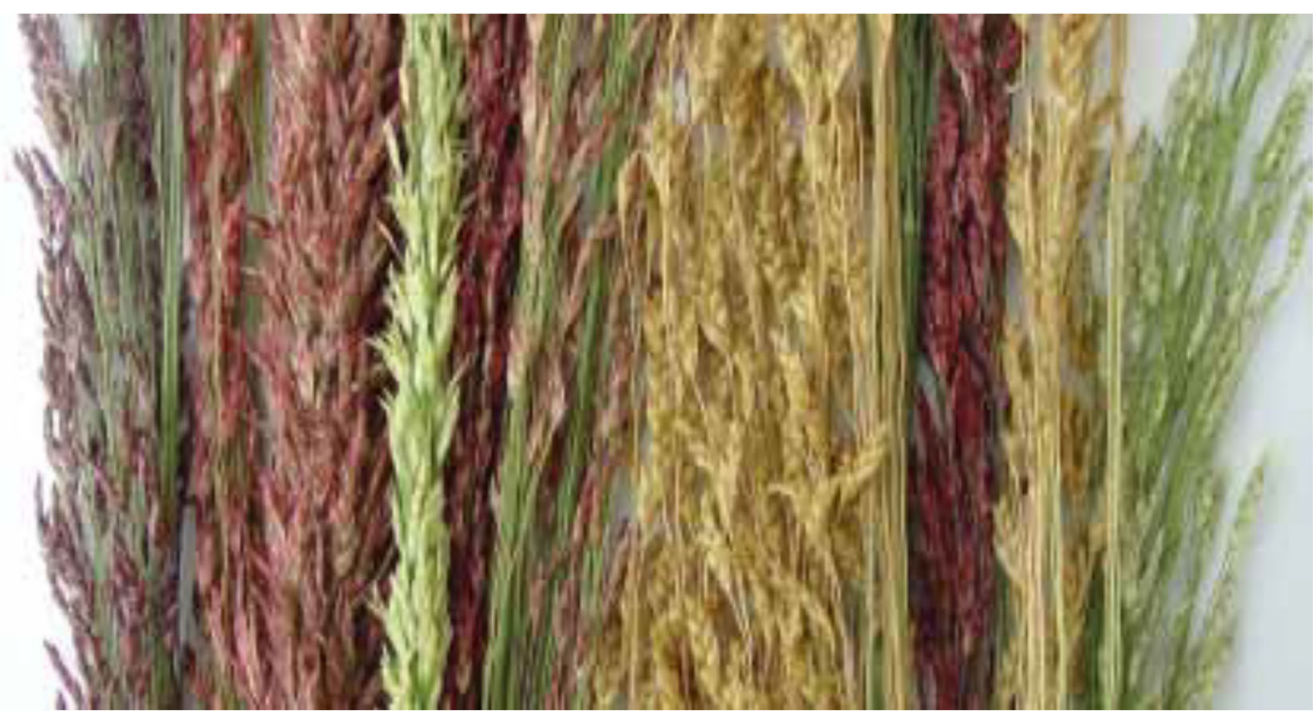

Figure 1: Panicle of wild Tef. Source: DZARC, (2008)

\subsection{Importance of Tef}

Tef is used in various forms by Ethiopians, the dominant form of usage is injera, unleavened pan cake made of tef flour, which is the mainstay of Ethiopian diet, and also it is consumed in the form of porridge and bread. The nutrient contents of tef are high and primary constituent of protein, amino acids and carbohydrates. Amount of concentration of calcium, iron and zinc more in tef than corn, wheat, or rice (Baye, 2014). In addition, as a cash crop, both the grain and straw of tef fetch higher prices than the respective products from other cereals. Consumers prefer tef not only because it makes good quality 'injera', a pancake-like soft bread, but also because it is nutritious due to its high protein and mineral content (Bultosa et al., 2002). Furthermore, the absence of gluten makes tef an alternative food for people suffering from celiac disease (Spaenij et al., 2005). According to Zung, (2004) stated that is particularly important in dealing with diabetes and assisting with blood sugar control. The straw of tef is nutritious and highly preferred feed for livestock compared to the straw of other cereals particularly during dry season. Besides its local use, it is the major cash earning crop for the farming community as market price for both its grain and straw is higher compared to other cereal crops, also among export commodity at national level.

\subsection{Limitations of the Crop}

Regardless of its versatility in adapting to extreme environmental conditions, the productivity of tef is low in Ethiopia at 1.7 tons ha- 1 as compared to 3.9 tons $\mathrm{ha}^{-1}$ for maize (CSA 2018). The small size of tef seed poses problems during sowing, and indirectly during weeding and threshing. At sowing the very small seed size makes it difficult to control population density and its distribution. This remains true whether one broadcasts the seed by hand, uses a broadcaster or a seed driller (Seyfu, 1997). The uneven plant stand after germination has an impact on nutrient use efficiency of the crop and crop yield. Owing to the scattered plant stand, farmers find it difficult to use mechanical weeding implements and are forced to either hand-weed or use chemical herbicides. Threshers or combine harvesters are used to thresh tef, however, seed loss is incurred because tef seed is very small and light and gets blown away. 


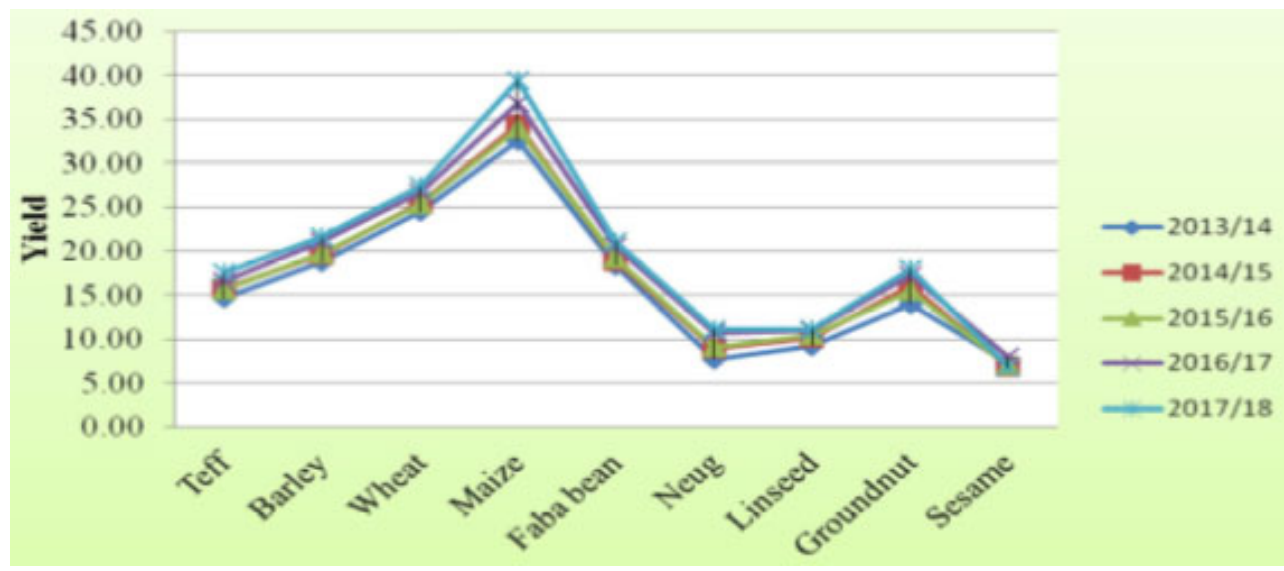

Figure: 2 Tef Productivity $\left(\mathrm{Qha}^{-1}\right)$

Source: CSA, (2018)

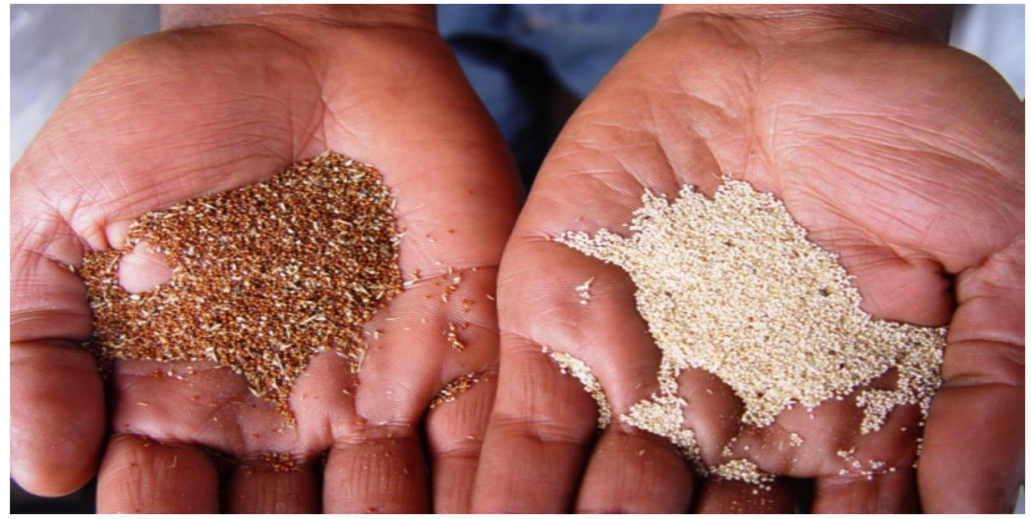

Figure 3: Types of Tef

Source: Tareke, (2009)

Lodging or the permanent displacement of the stem from the upright position is the major constraint limiting the productivity of the crop especially when it occurs during the grain-filling period, affects both the quality and quantity of the produce (Seyfu, 1993). Harvesting of the crop is difficult because of lodging. Since tef lodges heavily, it is not advisable to use higher rates of fertilizer to increase yield. The current landraces and cultivars used are not lodging resistant and the development of genetically lodging-resistant cultivars is essential (Seyfu, 1997).

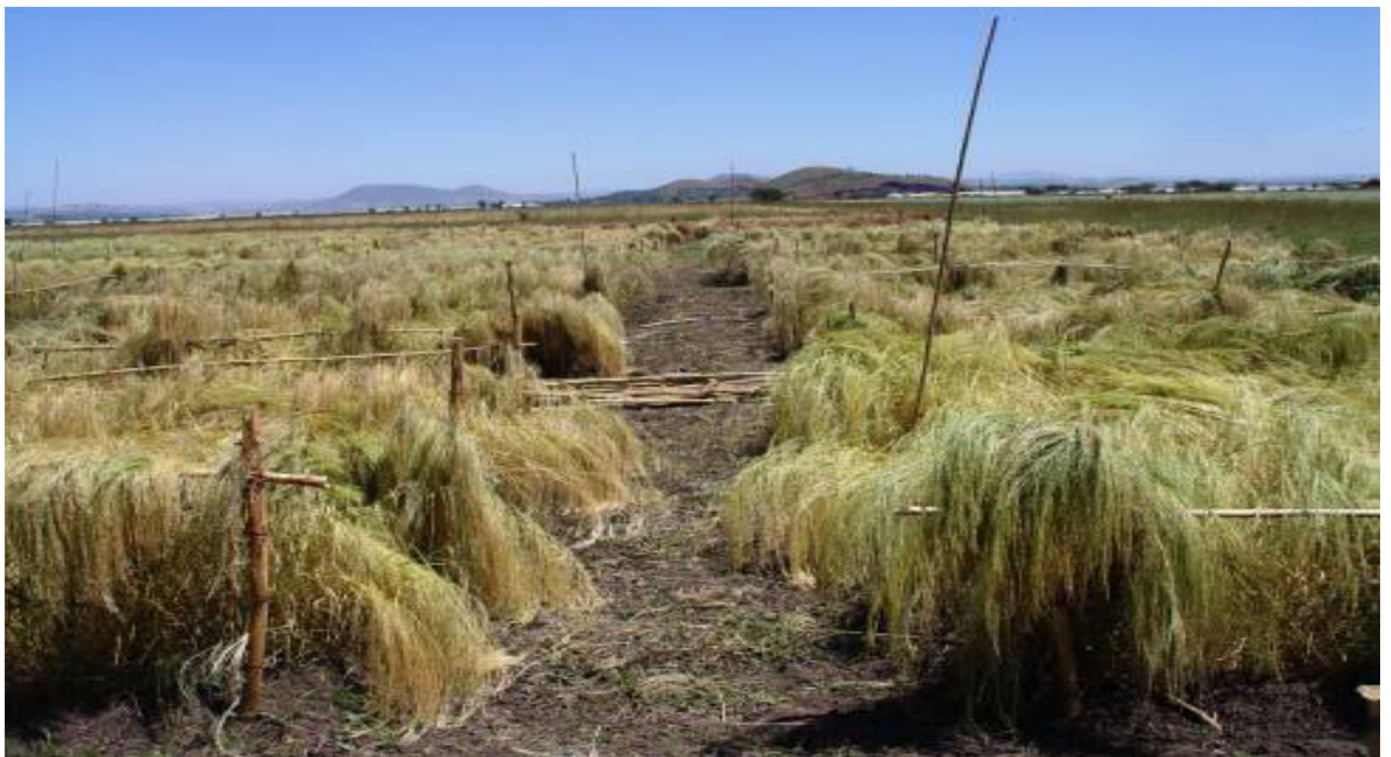

Figure 4. Lodged tef picture

Source: DZARC, (2008) 


\subsection{Increasing Small Seed Size Technique 2.5.1. Seed pelleting}

Pelleting is the process of enclosing the seed with small quantity of ingredient along with filter materials is coated to produce a globular unit of standard size to facilitate precision planting. It is methods envelop seed inside a small quantity of inert material just large enough to produce a globular unit of standard size to facilitate planting. The inert material creates natural water holding media and provides small amount of nutrient to young seedlings (Krishnasamy, 2003). Small and irregularly shaped seed can now be treated as larger and round-shaped thereby simulation of seed in the field is therefore easier (Harveson et al., 2007). Pelleting improves the chances of successful germination and seedling establishment under field condition and protect the seed borne fungal and insect attack finally contributing to increased seed yield (Bharathi et al., 2003). There are two components to a seed pellet: bulking coating material and binder. The bulking material can be either being a mixture of several different mineral and/or organic substances or a single component. The coating material changes the size, shape and weight of the seed. Desirable characteristics of a good coating material include: uniformity of particle size distribution, availability of material, and lack of phytotoxicity. The second component, the binder, holds the coating material together (Harveson et al., 2007).

Binder concentration is critical because too much binder will delay germination, whereas too little binder will cause chipping and cracking of pellets in the planter box, which can cause skips and/or wide gaps in the plant rows. Many different compounds have been used as binders, including various starches, sugars, gum Arabic, clay, cellulose, vinyl polymers and even water (Burgesse, 1949). As the demand for pelleted seeds increased, so did the number of companies that produced pelleted seeds, increased competition of pelleted seed market has fostered the development of more effective pellets with greater capabilities and wider plating characteristics. Pellet improvements over the last 10 years include increased $\mathrm{O}_{2}$ penetration/availability, wider pellet density range, pellet loading, better field visibility. Because of the large increase in volume obtained when seeds are pelleted, pellets have been shown to be effective carriers of plant protectant (pesticides) (Muller and Berg, 2008). The same plant protectant that are often deleterious if applied directly to the seed can be "carried" in the seed pellet. The act of applying a plant protectant in a band within the pellet is known as "pellet loading". The pellet either acts to "dilute" the negative impact of plant protectant as it moves through the pellet to the seed, or acts as a barrier to prevent direct seed contact. Active products can thus be "loaded" onto the seed while minimizing adverse seed germination effects (Harveson et al. 2007).

\subsubsection{What kind of seeds are pelleted}

Seeds of various sizes are commercially pelleted, from relatively large seeds like onion and tomato to very small seeds like lettuce species and tef. For onion, the seed can increase in weight 6-fold due to pelleting; there are approximately 230 raw seeds per gram, and after pelleting the diameter may be $13.5 / 64$ th of an inch $(0.54 \mathrm{~cm})$. The volume for 1000 propagules is $3.7 \mathrm{~cm}^{3}$ for raw seed compared to $18.0 \mathrm{~cm}^{3}$ after pelleting. The smallest seed that seed dynamics pellets is Begonia. Median seed weight for raw begonia is 88,000 seeds per gram. After pelleting, the seed count can average 857 seeds per gram, an increased mass of over 100-fold.

\subsubsection{Pelleting material}

The materials used for coating should be perfect as the physical integrity of coating is decided by the type of adhesive and this is highly influenced during handling, transport and planting operations of the pellets. According to Howieson et al., (1987) found that the use of poly vinyl pyorrolidone (PVP) is appropriate for coating seeds that will be submitted to impact and abrasion during sowing or those which will be mixed with fertilizers. The coating material must be porous to allow movement of air to the seed, must easily breakdown when it comes in contact with soil moisture, nontoxic, beneficial and harmless to both seed and rhizosphere (Veena, 2007). The methyl celluloses, such as Methofas ${ }^{\circledR}$, Cellofas ${ }^{\circledR}$ and Methocel ${ }^{\circledR}$, are non-ionic cellulose ethers, soluble in water, which are recommended because they are semi-synthetic polymers that are economic due to their low use concentrations (Scott, 1989). Silva et al., (2002) also studied bentonite as a binder for pelleting lettuce seeds, at different combinations of bentonite, they found that bentonite aggregates the coating particles and that a $100 \%$ use of bentonite, after drying at $36^{\circ} \mathrm{C}$, improved seed quality. There has been a variety of promising products used for pelleting seeds, including microcrystalline cellulose (microcellulose), which is a thin, white, odorless, crystalline powder, originating from partial acid hydrolysis that causes depolymerization of the cellulose chains However, other products are being tested as a coating for pelleting seeds, but their viability will depend on their compatibility with the binders and other materials on the seeds (Almeida, 2004). 
Table 1. Types of seed pelleting.

\begin{tabular}{|l|l|}
\hline \multicolumn{1}{|c|}{ Type } & \multicolumn{1}{c|}{ Materials Used } \\
\hline Innoculant Pelleting & Biofertilizer viz, Rhizobia, PSB, Azospirillum, Azotobactor, VAM. \\
\hline Protective Coating & $\begin{array}{l}\text { Biocontrol agent like Rhizobacteria bataticola, Bacillus sp. Streptomycis sp. } \\
\text { pesticides, fungicides. }\end{array}$ \\
\hline Herbicide Coating & $\begin{array}{l}\text { Filler antidote or absorbent coating, Herbicide antidote like 1.8 napthalic, anahydride } \\
\text { (NA) }\end{array}$ \\
\hline Nutrient Coating & Coating with micro and macro nutrients. eg. ZnSO, FeSO $_{4}$, Borax \\
\hline Hydrophilic Coating & Starch graft polymers, magnesium carbonate \\
\hline $\begin{array}{l}\text { Oxygen Supplier } \\
\text { Coating }\end{array}$ & Peroxides of zinc and calcium \\
\hline
\end{tabular}

Source: Halmer, (2006)

A grower may have a very high yield in a particular field, but not be able to sell a high percent of the crop. Vegetables must meet the standards required by the industry, and demanded by consumers across the country. A uniform, nicely shaped product is usually a must. To get the highest percentage of your crop to meet these standards, precisely planting seed in the soil with the desired amount of space between each seed is critical (Zubair, 2011). Seed pelleting can increase the possibility that the seed will be placed in the soil with the most precision and accuracy possible. The idea behind seed pelleting is to take a seed that is comparatively light in density and oddly shaped and turn it into a seed with a pellet around it that makes that seed heavier, more uniform, and as perfectly round as possible. A planter will be able to plant that seed/pellet in the most accurate and precise way that is mechanically possible_(Zubair, 2011). Creating a pellet is both a science and an art: most of the science comes when selecting the powders and adhesive used to create the pellet around the seed. The materials should form a pellet structure that is porous enough to provide immediate oxygen to the germinating seed, and absorb water in a way that is most beneficial to the seed. It is necessary sometimes to have a mixture of 4 or more powders in order to achieve the desired characteristics and also end up with the desired pellet density (Zubair, 2011).

The adhesive is also very important, as it make to be strong enough to hold the powder together, without making the pellet so hard that it slows the germination process. You can also go one step further by putting together the right combination of adhesives and powders to create a pellet that actually splits open much like an egg cracks open. This splitting action is said to lead to even faster oxygen availability and thus less stress on the germinating of seed(Zubair, 2011). There are a couple of ways to create a pellet around a seed, but today the most common method was taken from the candy industry. In this method, seed is placed in a large rolling pan like the one pictured below. The pan is continuously turning and tumbling the seed during this process. The pelleter sprays water until the seed surface is wet. After that, he sprinkles the pelleting powder over the wet, tumbling seed (Zubair, 2011). The powder sticks to the wet seed. The pelleter then sprays adhesive until the seed and powder is again wet. During the process the pellets are removed from the rolling pan several times in order to run them over a sizing screen so that smaller pellets can be built up, while any larger pellets wait outside the pan. This is done until all pellets are exactly the same standard size. Knowing when and how much adhesive to add, and when and how much powder to add is an art that takes some time and practice to perfect (Osted, 2011). Several companies are starting to use machinery that is more mechanized, using less art, but the method described is still the most common pelleting method used in the industry today (Osted, 2011 )
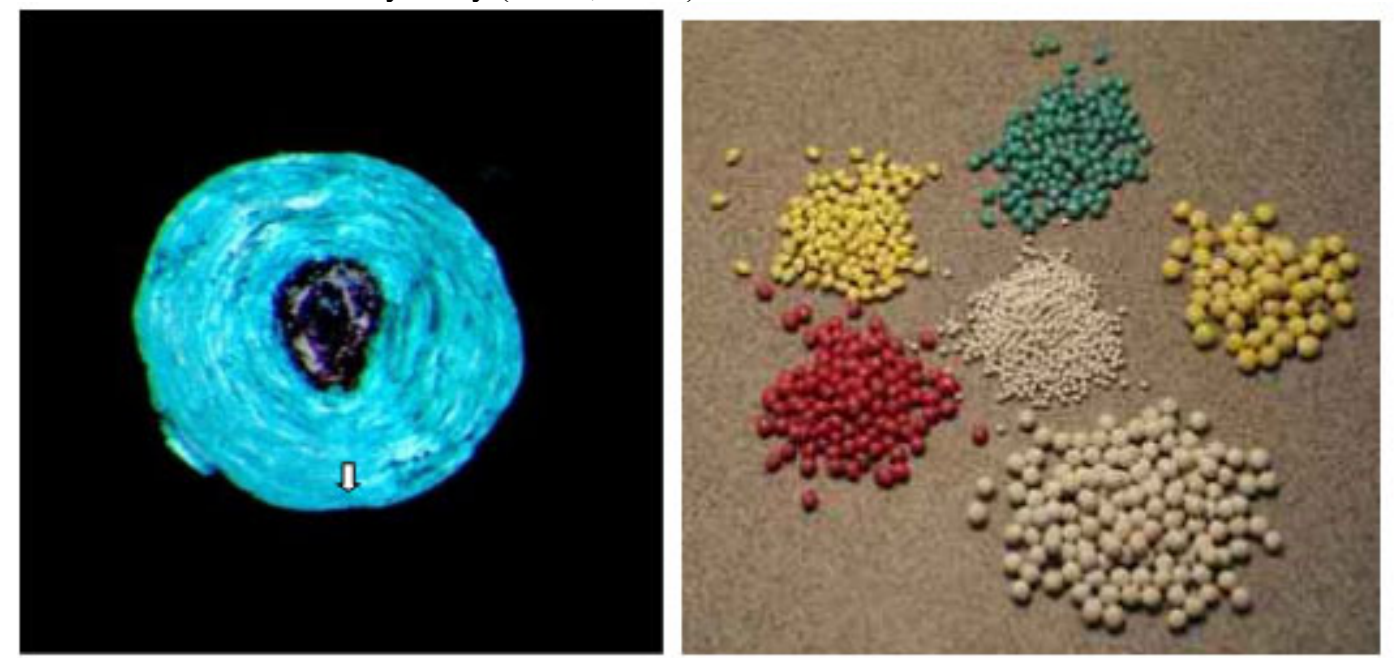

Figure 5: Seed pelleting technology.

Source: Osted, (2011) 


\subsection{Uses of Seed Pelleting}

Many crop seeds are small and irregular in shape which does not permit the accurate metering by mechanical planting equipments. Pelleting improves the chances of successful germination and seedling establishment under field condition (Bharathi et al., 2003). It protects the seed borne fungal and insect attack finally contributing to increased seed yield (Taylor and Eckenrode, 1993). The original purpose of pelleting was to increase the apparent seed size and weight to alter seed shape for precision planters. In addition to this, pelleting also provides the opportunity for greater loading of material around the seeds and the spatial orientation of active ingredient can be varied within the pellet (Upadhyaya, 2013). Due to small size varied shape of tef, performance of pelleted seeds is influenced by several factors viz., seed coating material, soil and aerial environment.

\subsubsection{Seed pelleting for accurate sowing.}

Further major advantages are that even the smallest seeds when encapsulated in the frozen pellets can be accurately metered during planting operations, precisely positioned and properly spaced. Thus, the amount of seed required can be reduced to a fraction of that previously needed, particularly in view of the significantly improved rate of germination (Tareke, 2010). Precise rows of accurately spaced plants can be attained so as to facilitate subsequent mechanical weeding and cultivation easily done, hence each plant can be assured proper growing room for optimum production, thereby thinning operations can be rendered unnecessary (Tareke, 2010).
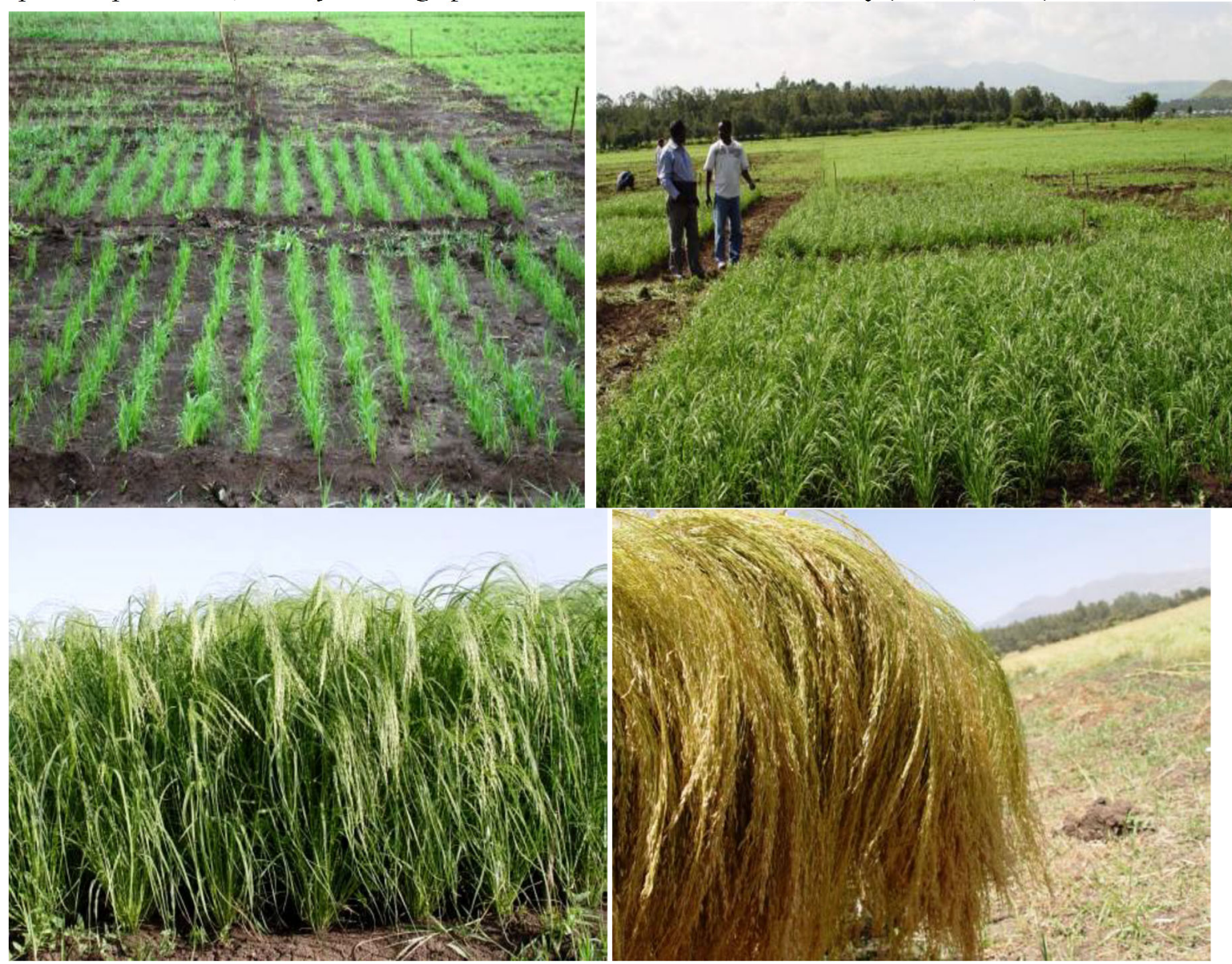

Figure 6: pelleted seed tested.

Source: DZARC, (2008)

In view of the foregoing, it should be apparent that the instant invention provides an improved method for planting seeds in which the pellets are particularly adapted for planting crops requiring shallow covering, without regard to soil moisture content. Although the invention has been herein shown and described in what is conceived to be the most practical and preferred method and embodiment, it is recognized that departures may be made there from within the scope of the invention (Tareke, 2010).

\subsection{Effects Seed Pelleting on Germination}

Seed pelleting are physiological seed enhancement methods used on many small seed crops to improve rate of seed germination and seedling performance so as to reduce seed wastage and facilitate the delivery of seeds (Kubik, 2002). Pelleting of seeds with nutrients in pelleting material raised the yield of tomatoes through accelerated growth and development (Konstantinov, 1983). Moreover, during germination tests, it was observed that pelleted 
seeds gave seedlings with deeper green and larger leaves as compared to unpelleted seeds. However, pelleted seeds required less time to germinate as compared to unpeelleted or uncoated seeds. Moreover the germination percentage was significantly $(\mathrm{P}<0.05)$ higher in pelleted seeds than unpelleted seed, further more appears essential for enhanced germination rate and seedling performance (Petch, 1991).

Seeds pelleted with N, P, K, Fe, Cu, Mn, B. and Zn gave 3.4 per cent higher field germination over unpelleted seeds (Konstantinov and Petkov, 1982). According to Balaji, (1990) reported that the seeds pelleted with Acacia nilotica improved water holding capacity and pelleting act as a buffer to establish the best soil crop relationship thereby enhancing germination and development of soybean and other crops. Golakiya (1992) reported that pelleting groundnut seeds with polyvinyl alcohol, polyacrelamide and polyacerilic acid improved seed germination even at lower soil water potential. Polyacrelamide was most effective out of three polymers, thus, polymer seed pelleting can be readily used to combat drought whereas, pelleting with lime significantly increased plant growth nodulation, besides protecting the inoculated rhizobia (Eyini and Tayakumar, 1993). Pelleting of wheat seeds with P. syringae and Erhinia hesbicola prevented the crop against Fussirium nivale and pythium and also enhanced the field emergence, plant weight, root length compared to control (Adethyi, 1992).

Bellary onion seeds pelleted with vermicompost, biofertilizers, DAP and micronutrient mixture recorded increased plant height, number of leaves and bulb yield (Ahamed Raza, 1997). According to Mani, (1997) reported that pelleting of seeds with macro and micro nutrients + biofertilizers exhibited quality seedling attributed for elite seedling production in Acacias. Balasubramanian et al., (1998) reported highest fruit yield of tomato at 100 per cent NPK plus $(50 \mathrm{~kg} / \mathrm{ha})$ plus borax $(10 \mathrm{~kg} / \mathrm{ha})$ plus composted coir pith $(5 \mathrm{t} / \mathrm{ha})$. Suman (2002) revealed that seeds pelleted with $\mathrm{ZnSO}_{4}$ with or without filler material recorded significantly higher plant height at 50 per cent flowering $(69.04 \mathrm{~cm})$ and harvest $(81.11 \mathrm{~cm})$ in sunflower.

\subsection{Effect of Pelleted Seed on Plant Height}

Significant differences were reported between the plant heights at different sampling dates throughout the experimental period (Karam, 2004). Variation on plant height due to seed pelleting were detected throughout the experimental period with the exception of sampling date 51 and 93. Farmyard manure pelleting resulted in the tallest plants compared to clay pelleting and the control through the experimental period; also it is increased plant height by $11 \%$ over clay pelleting and by $15 \%$ over the control (Karam, 2004).

Table 2. The effect of three types of pellets on plant height on tef crops $(\mathrm{cm})$.

\begin{tabular}{|l|l|l|l|l|l|l|}
\hline \multirow{2}{*}{ Treatment } & \multicolumn{5}{|c|}{ Days After sowing } & Means \\
\cline { 2 - 8 } & $\mathbf{3 7}$ & $\mathbf{5 1}$ & $\mathbf{6 5}$ & $\mathbf{7 9}$ & $\mathbf{9 3}$ & \\
\hline Farmyard manure pelleting & $17.36^{\mathrm{a}}$ & $21.13^{\mathrm{a}}$ & $30.80^{\mathrm{ab}}$ & $37.71^{\mathrm{a}}$ & $48.91^{\mathrm{a}}$ & 25.18 \\
\hline Clay pelleting & $16.61^{\mathrm{ba}}$ & $20.74^{\mathrm{b}}$ & $30.13^{\mathrm{ab}}$ & $35.07^{\mathrm{ab}}$ & $38.28^{\mathrm{b}}$ & 24.17 \\
\hline Control & $13.51^{\mathrm{c}}$ & $19.17^{\mathrm{bc}}$ & $27.49^{\mathrm{c}}$ & $32.82^{\mathrm{c}}$ & $36.14^{\mathrm{bc}}$ & 21.83 \\
\hline $\mathrm{Pr}>\mathrm{F}$ & 0.16 & 0.60 & 0.60 & 0.379 & 0.185 & \\
\hline $\mathrm{CV}(\%)$ & 16.77 & 12.82 & 14.83 & 12.04 & 17.85 & \\
\hline
\end{tabular}

Source: Karam, (2004).

\subsection{Effect on Seed Pelleted on the Plant Density}

The effect of pelleting on number of plants showed that in the following table shows, at day 65 there was a significant difference between the pelleting techniques. This may be attributed to the increased photosynthesis and hydrolytic process in this period, but in the day 37, 51, 79, and 93 there was no significant (Karam, 2004). Pelleting beside conserve moisture around roots, it also contributes by nitrogen found in manure. The report was in accordance with the result revealed by Shama et al., (1969) who stated that nitrogen rates were influence the number of plant.

Table 3. Mean effect of pelleted seed on plant density on tef crops (plant/pot).

\begin{tabular}{|l|l|l|l|l|l|l|}
\hline Treatment & \multicolumn{5}{|c|}{ Days } & Means \\
\hline Farmyard manure pelleting & $\mathbf{3 7}$ & $\mathbf{5 1}$ & $\mathbf{6 5}$ & $\mathbf{7 9}$ & $\mathbf{9 3}$ & Mean \\
\hline Clay pelleting & $9.63^{\mathrm{a}}$ & $9.78^{\mathrm{a}}$ & $9.78^{\mathrm{a}}$ & $9.78^{\mathrm{a}}$ & $9.78^{\mathrm{a}}$ & 9.75 \\
\hline Control & $9.48^{\mathrm{a}}$ & $9.48^{\mathrm{a}}$ & $9.48^{\mathrm{b}}$ & $9.48^{\mathrm{a}}$ & $9.48^{\mathrm{a}}$ & 9.48 \\
\hline P $>$ F & $8.63^{\mathrm{a}}$ & $8.70^{\mathrm{a}}$ & $8.74^{\mathrm{bc}}$ & $8.6296^{\mathrm{a}}$ & $8.70^{\mathrm{a}}$ & 8.70 \\
\hline CV (\%) & 0.09 & 0.06 & 0.04 & 0.08 & 0.083 & \\
\hline
\end{tabular}

Source: Karam, (2004).

\subsection{Effect of Seed Pelleting on Seed Yield}

Increased germination and seed yield were noticed due to pelleting of seed with urea and formaldehyde (Usmanov et al., 1981). In the field trials of legumes with various seed treatment, seed pelleting had a significant positive 
influence on emergence and seed yield (Zubal, 1986). According to Narasimha, (1994) noted increased seed yield and quality of the resulted seeds of tef crop raised with seeds pelleted with biogas slurry at $500 \mathrm{~g}$ per $\mathrm{kg}$. Srimathi et al., (2002) reported that pelleting the seeds with $\mathrm{ZnSO} 4$ at $250 \mathrm{mg}$ per $\mathrm{kg}$ of seed improved the initial seed quality and its production potentiality. According to Golakiya, (1992) reported that pelleting seeds with polyvinyl alcohol, polyacrelamide and polyacerilic acid improved seed germination thereby yield of seed, even at lower soil water potential. Polyacrelamide was most effective out of three polymers. Thus, polymer seed pelleting can be readily used to combat drought whereas, pelleting with lime significantly increased plant growth nodulation, besides protecting the inoculated rhizobia (Eyini and Tayakumar, 1993). Pelleting of wheat seeds with $P$. syringae and Erhinia hesbicola prevented the crop against Fussirium nivale and pythium and also enhanced the field emergence, plant weight, root length compared to control (Adethyi, 1992).

Sorghum seeds pelleted with four different fertilizer increased the germination per cent. In green house, $\mathrm{KCl}$, single superphosphate and lime gave better results than untreated seeds (Magalhaes et al., 1994). Sharma (1995) reported that soil application of calcium increased the plant height of tomato and number of branches per plant. Verma et al. (1995) observed highest marketable tomato fruits yield of 285.88 quintals per hectare when $10 \mathrm{~kg}$ zinc per hectare was applied. Bose and Tripathi (1996) reported improvement in growth and yield (plant height of $81.56 \mathrm{~cm}$, heighest number of branches of 19 per plant and number of fruits per plant) of tomato Cv. Pusa Ruby at combined application of micronutrients ( $\mathrm{Zn}, \mathrm{Mn}, \mathrm{Fe}$ and B) at 30 and 60 days after transplanting.

\section{CONCLUSION AND RECOMMENDATION}

Tef seed is small and its size varies, making sowing more difficult. The small size of tef seed poses problems during sowing, and indirectly during weeding and threshing. At sowing the very small seed size makes it difficult to control population density and its distribution. With tef seed pelleting, the achievements with regard to the pelleting technique so far are encouraging. Therefore, there is a need for further optimization of the pellet manufacturing technique. The pelleting technique increases and homogenizes seed size, but it is essential to determine the physical and physiological characteristics of pelleted seeds. The physiological analysis consisted of: first germination count, final germination, speed emergence index, and seedling emergence. Pellet improvements over the last 10 years include increased $\mathrm{O}_{2}$ penetration/availability, wider pellet density range, pellet loading, better field visibility. Because of the large increase in volume obtained when seeds are pelleted, pellets have been shown to be effective carriers of plant Protects. Generally application seed pelleting technology for small seed size crops particularly, tef is important for proper planting and maintain planting density of the crop. To this end, research for scientific evident is needed to this technology in the future.

As a recommendation, seed Pelleting is very important techniques to increase precision farming thereby increases the economics of the country, resulted interns livelihood economies by saving quantity of seed required per hectares. It is a new technology of making seeds bigger to increase the singling of seeds to ensure precision planting. Governments and seed processing companies have to play a great role in awareness creation about seed pelleting and its importance in crop production. Researchers have the responsibility to investigate the potential of pelleted seed in yield agricultural system and in improvement of agronomic practices.

\section{REFRENCES}

Adethyi F, 1992. Antagonistic potential of Pseudomonas syringae and Erwinia herbicolaon wheat seeds. Indian Journal of mycology and plant pathology. 22: 250-254.

Agwah M, and Mahmoud H, 1994. Effect of some nutrient sources and cultivars on tomato fruit set and yield. Bullet of Faculty of Agriculture. 45: 137-148.

Ahamed R, 1997. Seed technological studies on Bellary onion (Allium cepa L (Agri.) Thesis, Tamil Nadu Agric. Univ., Coimbatore, India.

Balaji D, 1990. Studies on the seed soil relationship in certain crops paddy, green gram, soybean, red gram, sunflower, groundnut and cotton. Thesis, Tamil Nadu Coimbatore, India.

Balasubramaniam P, Mani A, Duraiswamy, and Kandaswami, 1998. Effect of organic and inorganic nutrients on yield and uptake of tomato in Alfisols. South Indian Horticulture. 46: 143-147.

Berhanu F, 2001. Draft Report on Evaluation of Rain Water Harvesting Technologies in Ayub and Jarota Kebele Association Kobo Wereda. Ethiopian Rainwater Harvesting Association, Kobo, Ethiopia.

Bose U, and Tripathi S, 1996. Effect of micronutrients on growth, yield and quality of tomato cultivars. Crop Research. 12: 61-64.

Bultosa G, Hallan, Taylorjrn, 2002. Physico-chemical characterization of grain tef [Eragrostis tef (Zucc.) Trotter] starch. Starch-Starke 54:461-468.

Central Statistics Agency (CSA), 2018. Volume I. Report on Area and Production of Crops. Agricultural Sample Survey, Addis Ababa, Ethiopia, April, 2018.

Department of Plant Protection Quarantine and Storage, 2007. Campaign for 100\% Seed Treatment. August 31, 2017. 
Golakiya B, 1992. Hormonal treatment and seed pelleting to combat the drought. Drought response of groundnut: Volume I. Advance Plant Science. 5: 511-514.

Karam Ashraf, Eldeen Ahmed and Boush, 2004. Effect of Seed Pelleting and Water Regime on the Upper Nile University. Performance of Some Forage Species, May17, 2003.

Kebebew A, Zeid M, Belay G, Tefera H, Sorrells M, 2011. Breeding tef [Eragrostis tef (Zucc.) Trotter]: conventional and molecular approaches. Plant Breeding. 130: 1-9.

Kostantinov G, and Petkov P, 1982. Effect of pelleting on direct sown onion seeds. Grandianarshai Lozarska Nauka, naak. 6: 26-30.

Konstantinov G .1983. Transplantless growing of cv. Drouzhba tomatoes using pelleted seeds. Gradinarska Ii Lozarska Nauka. 20 (4): 53-57.

Mani, G, 1997. Seed technological studies in Acacia nilotica and Acacia leucophloea. Thesis, on Agriculture, India.

Mulu A, 1993. Use of excised-leaf water content in breeding tef [Eragrostis tef(Zucc.) Trotter] for moisture stress areas. Acta Agronomy Hung. 42: 261-265.

Petch G, Maude R, White J, 1991. Effect of film-coat layering of metalaxyl on the germination of carrot seeds, their emergence and the control of cavity spot. Crop Protection. 10: 117-120.

Piccinin D, 2002. Tef is major food of Ethiopian. http://ethnomed.org/clinical/nutrition May 27, 2017).

Seyfu K, 1993. Tef (Eragrostis tef): Breeding, Agronomy, Genetic Resources, Utilization, and Role in Ethiopian Agriculture. Institute of Agricultural Research, Addis Ababa, Ethiopia.

Seyfu K, 1997. Tef: [Eragrostis tef (Zucc.) Trotter]: Promoting the Conservation and Use of Underutilized and Neglected crops. Institute of Plant Genetics and Crop Plant Rsearch, Gatersleben/International Plant Genetic Resources Institute, Rome, Italy.

Shiferaw B, 1991. Study of Drought Tolerance in Tef (Eragrostis tef (Zucc.)Trotter). University of London, London.

Spaenij-Dekking L, Kooy-Winkelaar Y, Koning F, 2005. The Ethiopian cereal tef in celiac disease. https://doi.org/ 353:1748-1749.

Srimathi P, Malarkodi K., Geetha R, and Krishnaswamy V, 2002. Nutrient pelleting to augment quality seed production in soybean. Seed Research.. 30:186-189.

Suman, N. 2002. Influence of seed pelleting on storability, crop growth, seed yield and quality of sunflower (Helianthus annus L.) cv. Morden. M. Sc. (Agri.) Thesis, Univ. Agric. Sci., Dharwad.

Tareke, 2009. CIIFEAD forum seminar. April, 2009

Tareke B, 2010.Sasakawa Africa Association, Regional Office, Addis Ababa, Ethiopia. January, 1-13, 2010.

Usmanov S, Budhokov U, Ostrobro B, 1981. Pelleting of cotton seeds with urea and formaldehyde compounds. Abstract. 4: 29-92.

Vavilov N, 1951. The origin, variation, Immunity and Breeding of cultivated plants. Ronald Press, New York. [Translated from Russian by Sarrchester, K].

Verma S, Singh S, and Awasthi C, 1995. Response of zinc and boron fertilization on yield and quality of tomato fruits at different stages of picking. Vegetable Science. 22: 5-8.

Yini M, and Tayakumar M, 1993. Effect of seed pretreatment on the growth and nodulation of green gram plant under paper mill effluents irrigation. Indian Journal Eco. 20:161-164. 